\title{
Prognostic Factors Influencing the Survival of Patients with Metastatic Non-Small Cell Lung Cancer in the Moroccan Population: Retrospective Study of 405 Cases
}

\author{
Lamyae Nouiakh1" ${ }^{*}$, Karima Oualla1, Mariam Atassi', Imane Ouafki', Soumia Berrad1, \\ Hayat Erraichi', Lamiae Amaadour', Zineb Benbrahim1', Samia Arifi', Samira El Fakir ${ }^{2}$, \\ Nawfel Mellas ${ }^{1}$
}

${ }^{1}$ Department of Medical Oncology, Hassan II University Hospital, Fez, Morocco

${ }^{2}$ Epidemiology Laboratory, Clinical Research and Community Health, Fez, Morocco

Email: *nouiakhlamyae@gmail.com

How to cite this paper: Nouiakh, L., Oualla, K., Atassi, M., Ouafki, I., Berrad, S., Erraichi, H., Amaadour, L., Benbrahim, Z., Arifi, S., El Fakir, S. and Mellas, N. (2021) Prognostic Factors Influencing the Survival of Patients with Metastatic Non-Small Cell Lung Cancer in the Moroccan Population: Retrospective Study of 405 Cases. Advances in Lung Cancer, 10, 1-10.

https://doi.org/10.4236/alc.2021.101001

Received: January 7, 2021

Accepted: March 8, 2021

Published: March 11, 2021

Copyright $\odot 2021$ by author(s) and Scientific Research Publishing Inc. This work is licensed under the Creative Commons Attribution International License (CC BY 4.0).

http://creativecommons.org/licenses/by/4.0/ (c) (i) Open Access

\begin{abstract}
Introduction: Non-small cell lung cancer is the most common lung cancer. Despite the therapeutic advances, its prognosis is very reserved. Aim: Determine the different prognostic factors of patients with metastatic non-small cell lung cancer and their correlation with patient survival. Methods: A retrospective study was conducted at the medical oncology department of Hassan II University Hospital in Fez, collecting 405 patients during a period of 10 years, from January 2008 to January 2018. The statistical analysis of the results was done by the software SPSS version 23, the survival was calculated by the Kaplan-Meier method. The Cox method was used to study prognostic factors. Results: The average age of our patients was 59 years, with a sex ratio $\mathrm{M} / \mathrm{F}$ of 6.1. In multivariate analysis, we found a significant correlation between the deterioration of survival and an age greater than 75 years $(\mathrm{p}=$ $0.023)$, a general degraded state $(p<0.001)$, presence of a biological inflammatory syndrome $(\mathrm{p}<0.001)$, anemia $(\mathrm{p}<0.001)$ and hypoalbuminemia $(\mathrm{p}<$ 0.001). In addition, no significant association was found in patients with toxic habits or multiple metastatic sites. Conclusion: The prognostic factors of metastatic NSCLC in our patients were PS, age, anemia, hypoalbuminemia and inflammatory syndrome. We propose to validate all the factors identified by retrospective studies by prospective studies in order to guarantee the best chances of survival for patients.
\end{abstract}

Keywords

Non-Small Cell Lung Cancer, Prognostic, Survival 


\section{Introduction}

Bronchopulmonary cancer is the most common cancer in the world and is the leading cause of cancer death in men [1]. The number of incident cases is constantly increasing (2.1 million new cases in 2018 versus 1.6 million in 2008). The mortality rate was estimated at 1.8 million deaths in 2018 versus 1.4 million in 2008 [1]. Nationally, according to data from the cancer registry for the Grand Casablanca region, lung cancer is the most common cancer in humans with a rate of 23\% of cases recorded during the period between 2008 and 2012 [2]. Regarding the incidence of this cancer, there has been a significant increase in new cases over the years, especially advanced forms, which makes the prognosis poor. Considering the stage of the tumor at the time of diagnosis is the main prognostic factor [3].

Prognostic factors are defined as things that can predict a patient's prognosis before treatment is started. Several publications have been made in this direction, taking these factors into account is of great importance, more particularly in the choice of treatment. In this article, we will study these different factors and their influence on survival.

\section{Methods}

A descriptive retrospective study was carried out in the medical oncology department of the Hassan II University Hospital in Fez, collecting 405 patients with metastatic NSCLC over a period of 10 years, from January 2008 to January 2018. The inclusion criteria were: patients with histologically proven non-small cell lung cancer, classified as stage 4 . The exclusion criteria were: patients with nonhistologically proven NSCLC and incomplete medical records. Descriptive statistics were used to describe the characteristics of these tumors using the mean \pm standard deviation for continuous variables and frequencies for categorical variables. Survival was calculated by the Kaplan-Meier method. Cox's method was used to study prognostic factors. The significance level for all tests was set at 0.05 . Statistical analysis of the results was done by SPSS version 23 software.

\section{Results}

Between January 2008 and January 2018, we included 405 patients with metastatic NSCLC in the medical oncology department of CHU Hassan II in Fez. The average age of our patients was 59 years, the percentage of patients with an age greater than or equal to 70 years was $17.8 \%$. The majority of patients were male with a percentage of $86 \%$ (sex ratio M/F: 6.1). Smoking was the main risk factor (78\%), the notion of alcoholism and cannabis use was found in $12.8 \%$ and $8.1 \%$ of cases respectively. The notion of occupational exposure was reported in $4.2 \%$ of cases. The most common symptoms were cough (41\%), haemoptysis (33\%), dyspnea (29\%) and chest pain (20\%). 65.2\% of patients were in good general condition (PS 0 to 1 ) at the time of diagnosis. The most common histologic type 
was adenocarcinoma (59.5\%), followed by squamous cell carcinoma (22.5\%) then other carcinomas (18\%). According to the TNM classification, $62 \%$ of patients were classified as T4 and lymph node invasion N2 and N3 was found in 29\% and $35 \%$ of cases respectively. $39 \%$ of patients had more than one metastatic site after extension workup. The most frequent elective sites of metastases were: lung (50.4\%), bone (32.6\%) pleura (22\%), brain (21.2\%) and liver (17.5\%). All patients performed a biological workup including a count blood, an assay of the level of albumin, lactate dehydrogenase (LDH), alkaline phosphatase (ALP), calcium level and C-reactive protein (CRP); this assessment had demonstrated anemia in $58.8 \%$ of patients, hyperleukocytosis in $45.9 \%$ of cases, thrombocytosis in $13.8 \%$ of cases, hypoalbuminemia in $49.6 \%$ of cases, an increase in the level of $\mathrm{LDH}$ and ALP in $34.3 \%$ and $29 \%$ of cases respectively and hypercalcemia in $4 \%$ of cases.

The first-line treatment was essentially based on chemotherapy, it was indicated in $87.1 \%$ of which $83 \%$ of patients received a doublet based on platinum salts \pm BEVACIZUMAB (13\%) and 17\% received NAVELBINE as monotherapy.

Anti-EGFR TKIs were administered to $2.5 \%$ of patients with the EGFR mutation (Table 1). After an average number of 3 cures, the objective response rate was $18.6 \%$.

After a median follow-up of 18 months, the median progression-free survival (PFS) was 4.6 months and that of overall survival (OS) was 6.5 months (Figure 1).

In multivariate analysis, we found a significant correlation between the deterioration of survival and an age greater than 75 years $(p=0.023)$, a deteriorated general condition $(\mathrm{p}<0.001)$, presence of a biological inflammatory syndrome $(\mathrm{p}<0.001)$, anemia $(\mathrm{p}<0.001)$ and hypoalbuminemia $(\mathrm{p}<0.001)$. Furthermore, no significant association was found in patients with toxic habits or presenting several metastatic sites (Table 2 and Table 3 ).

Table 1. Patient characteristics.

\begin{tabular}{ccc}
\hline Characteristics & & Number (\%) \\
\hline \multirow{2}{*}{ Gender } & Male & $349(86.2)$ \\
& Female & $56(13.8)$ \\
Age & $<70$ years & $333(82.2)$ \\
& $>70$ years & $72(17.8)$ \\
& Smoking & $316(78)$ \\
Toxic habits & Alcoholism & $52(12.8)$ \\
& Cannabism & $33(8.1)$ \\
& Professional exposure & $17(4.2)$ \\
& Cough & $166(40.9)$ \\
Clinical signs & Hemoptysis & $134(33.1)$
\end{tabular}




\section{Continued}




Table 2. Univariate analysis of factors influencing overall survival.

\begin{tabular}{cccc}
\hline Characteristics & P-value & Odds-ratio (OR) & 95\% confidence interval \\
\hline Age $\geq 75$ years & 0.021 & 0.64 & {$[0.43-0.93]$} \\
Smoking & 0.731 & 0.95 & {$[0.73-1.24]$} \\
Professional exposure & 0.828 & 1.05 & {$[0.64-1.73]$} \\
PS > 1 & $<0.001$ & 1.73 & {$[1.37-2.19]$} \\
Anemia & $<0.001$ & 1.55 & {$[1.24-1.94]$} \\
Hyperleukocytosis & 0.626 & 0.94 & {$[0.75-1.18]$} \\
Thrombocytosis & 0.276 & 1.19 & {$[0.86-1.64]$} \\
Metastatic site > 1 & 0.318 & 1.11 & {$[0.89-1.39]$} \\
Hypoalbuminemia & $<0.001$ & 3.20 & {$[2.65-3.85]$} \\
Raised CRP & $<0.001$ & 2.98 & {$[2.21-3.45]$}
\end{tabular}

Table 3. Multivariate analysis of factors influencing overall survival.

\begin{tabular}{cccc}
\hline Characteristics & P-value & Odds-ratio (OR) & 95\% confidence interval \\
\hline Age $\geq 75$ years & 0.023 & 0.64 & {$[0.44-0.94]$} \\
PS $>1$ & $<0.001$ & 1.71 & {$[1.37-2.15]$} \\
Anemia & $<0.001$ & 1.57 & {$[1.25-1.96]$} \\
Hypoalbuminemia & $<0.001$ & 3.21 & {$[2.67-3.86]$} \\
Raised CRP & $<0.001$ & 2.99 & {$[2.23-3.46]$} \\
\hline
\end{tabular}

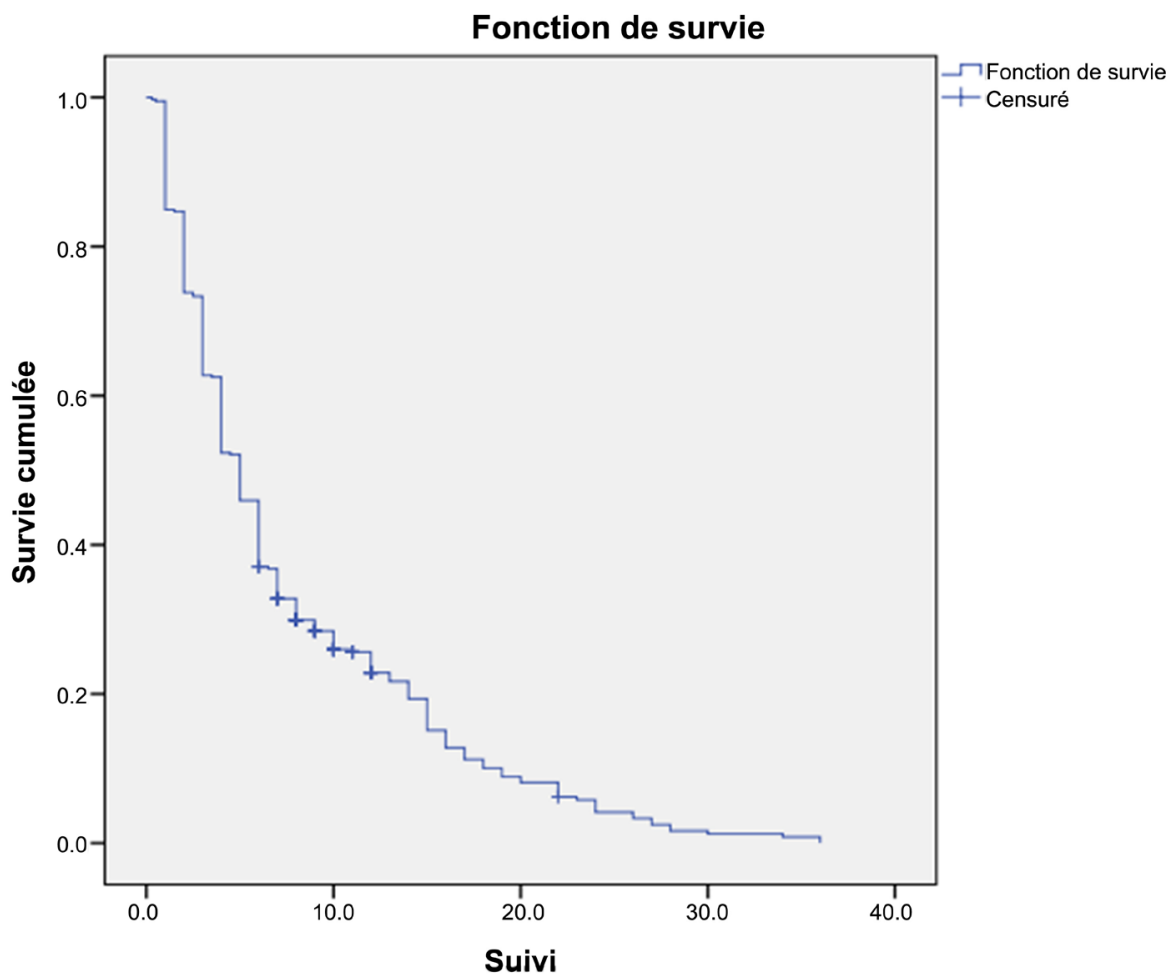

Figure 1. Curve of overall survival estimated according to Kaplan-Meier. 


\section{Discussion}

Lung cancer is the leading cause of cancer death worldwide, with 1.8 million deaths in 2018, which represents nearly 1 in 5 cancer deaths [1]. In men, it is the leading cause of death in countries in Europe, Asia and Africa [1]. The incidence of this cancer remains generally low in Africa, although it varies from medium to high between the countries of the North and the South, in particular in South Africa $(28.2$ in 100,000) and in Morocco (31.9 in 100,000) [1]. Among the prognostic factors widely studied in the literature are: the performance status; it is considered to be a powerful prognostic factor, this factor has been studied in several phase III studies, confirming the reproducibility of this factor with hazard ratios varying between 0.60 and 0.70 [4] [5] [6]. The 2nd clinical factor is sex; according to some authors, it has been shown in several studies that overall survival in women is much better than in men [7], this was confirmed by a meta-analysis [8] including 39 studies with more than 86,000 patients, this metaanalysis combined the odds ratios of the uni and multivariate analyzes and they were 0.79 and 0.78 , respectively; both $p<0.0001$ in favor of the female sex. Age is another factor that has been studied in several clinical trials, but there are few studies that have confirmed the prognostic significance of age $>70$ years on survival [9] [10]. In our study, we found a significant improvement in survival in patients in good general condition aged less than 70 years. On the other hand, no correlation has been demonstrated between gender and reduced survival. Smoking is also considered a poor prognostic factor, it has a negative impact on survival, proven in several studies [11] [12] [13], it has been shown in these trials that patients who smoked over $20 \mathrm{PA}$ are more likely to have aggressive and less differentiated histological types. And for those who smoked above $60 \mathrm{PA}$, the risk of developing distant metastases is $41 \%$ (95\% CI: 1.03 - 1.94) [12]. In our series, smoking was not associated with decreased survival on univariate analysis.

Another factor has also been studied; this is the histological type. Its role in predicting the prognosis remains controversial, according to Blanchon and his colleagues [14], a study was carried out including 5667 patients, showing that patients with squamous cell carcinoma had better survival $(\mathrm{p}<0.001)$ compared to those with large cell neuroendocrine carcinoma $(\mathrm{p}<0.001)$. Conversely, other authors have confirmed in studies that squamous cell carcinoma has a poor prognosis than adenocarcinoma [15] [16]. In our series, histological type was not correlated with survival $(\mathrm{p}=0.15)$. With regard to the number of sites and the location of metastases; few studies have been conducted in this direction, Wakelee and colleagues [17], have suggested that the presence of a single metastatic site in the lungs is a good prognosis. In our series, the presence of more than one metastatic site was not a factor in the decline in survival. The association between the presence of a biological abnormality and reduced survival has also been studied. Beginning with anemia; researchers have suggested that the presence of anemia before initiation of treatment is an independent prognostic factor for survival in patients with lung cancer and may be associated with higher 
mortality [8] [18] [19], this has been demonstrated in our study. The presence of hyperleukocytosis and thrombocytosis is significantly correlated with decreased survival [20] [21] [22], this is inconsistent with the results of our study; patients with these hematologic abnormalities at the time of diagnosis did not have a significant difference in survival compared to those with correct biology. Among the potential serum biomarkers, we cite lactate dehydrogenase (LDH) which is an enzyme released by rapidly growing tumors, it has a correlation with tumor burden. Recent studies have shown that a high level of LDH before the initiation of treatment is generally associated with poor results in terms of survival, its presence makes the prognosis poor especially when it is increased by 1 to 2.5 times the upper normal limit (ULN) [23] [24]. Serum albumin levels reflect the nutritional status of cancer patients; it is an important determinant of survival in many types of cancer. This parameter has been reported as a negative prognostic factor for survival in advanced NSCLC in several studies [25]. Serum CRP has been identified as a significant prognostic factor in patients with colorectal, esophageal and hepatic carcinoma [26]. However, the nature of this association in patients with metastatic NSCLC remains controversial at present, data from Alifano's study [27] did not reveal a significant difference in terms of survival between the groups of patients with high and normal CRP, however the results of a meta-analysis [28] including 8 studies with more than 1600 patients demonstrated that a high CRP level could predict the prognosis in patients with NSCLC. Our results demonstrated that elevated LDH, hypalbuminemia and inflammatory syndrome are unfavorable prognostic factors determining deterioration in survival in patients with NSCLC. Systemic anti-tumor treatment has shown its benefit in terms of survival versus supportive care. Several meta-analyzes that have been carried out in this direction [29] [30], showing the clear benefit of anti-tumor treatment on the survival of patients with metastatic NSCLC.

\section{Conclusion}

Through this retrospective study, the presence of these following factors (PS $>1$, age $>75$ years, anemia, hypoalbuminemia and elevated CRP) was associated with a poor prognosis, these factors must be taken into consideration to define optimal management and guide the clinician in the choice of the best therapeutic protocol, we propose as perspectives to validate all the factors identified in retrospective studies by prospective work in order to guarantee the patient the best chances of survival.

\section{Conflicts of Interest}

The authors declare that they have no competing interests.

\section{References}

[1] Bray, F., Ferlay, J., Soerjomataram, I., Siegel, R.L., Torre, L.A. and Jemal, A. (2018) Global Cancer Statistics 2018: GLOBOCAN Estimates of Incidence and Mortality 
Worldwide for 36 Cancers in 185 Countries. CA: A Cancer Journal for Clinicians, 68, 394-424. https://doi.org/10.3322/caac. 21492

[2] Karima, B. (2016) Le registre des cancers de la région du grand Casablanca pour la période 2008-2012. Edition 2016. Fondation Lalla Salma Prévention et Traitement des Cancers.

[3] Mountain, C.F. (1997) Revisions in the International System for Staging Lung Cancer. Chest, 111, 1710-1717. https://doi.org/10.1378/chest.111.6.1710

[4] Skarin, A.T., Herbst, R.S., Leong, T.L., Bailey, A. and Sugarbaker, D. (2001) Lung Cancer in Patients under Age 40. Lung Cancer, 32, 255-264.

https://doi.org/10.1016/S0169-5002(00)00233-6

[5] Salloum, R.G., Smith, T.J., Jensen, G.A. and Lafata, J.E. (2012) Survival among NonSmall Cell Lung Cancer Patients with Poor Performance Status after First Line Chemotherapy. Lung Cancer, 77, 545-549.

https://doi.org/10.1016/j.lungcan.2012.04.019

[6] Chermiti Ben Abdallal, F., Ben Ali, G., Sadok Boudaya, M., Mlika, M., Chtourou, A., Taktak, S. and Ben Kheder, A. (2014) Traitement et pronostic du cancer bronchique non à petites cellules au stade avancé. Revue des Maladies Respiratoires, 31, 214-220. https://doi.org/10.1016/j.rmr.2013.09.002

[7] Paesmans, M. (2008) Les facteurs pronostiques. Revue des Maladies Respiratoires, 25, 3S99-3S106. https://doi.org/10.1016/S0761-8425(08)82014-1

[8] Nakamura, H., Ando, K., Shinmyo, T., Morita, K., Mochizuki, A., Kurimoto, N. and Tatsunami, S. (2011) Female Gender Is an Independent Prognostic Factor in NonSmall-Cell Lung Cancer: A Meta-Analysis. Annals of Thoracic and Cardiovascular Surgery, 17, 469-480. https://doi.org/10.5761/atcs.oa.10.01637

[9] Albain, K.S., Crowley, J.J., LeBlanc, M. and Livingston, R.B. (1991) Survival Determinants in Extensive-Stage Non-Small-Cell Lung Cancer: The Southwest Oncology Group Experience. Journal of Clinical Oncology, 9, 1618-1626.

https://doi.org/10.1200/JCO.1991.9.9.1618

[10] O’Connell, J.P., Kris, M.G., Gralla, R.J., Groshen, S., Trust, A., Fiore, J.J., Kelsen, D.P., Heelan, R.T. and Golbey, R.B. (1986) Frequency and Prognostic Importance of Pre-Treatment Clinical Characteristics in Patients with Advanced Non Small Cell Lung Cancer Treated with Combination Chemotherapy. Journal of Clinical Oncology, 4, 1604-1614. https://doi.org/10.1200/JCO.1986.4.11.1604

[11] Yoshino, I., Kawano, D., Oba, T., Yamazaki, K., Kometani, T. and Maehara, Y. (2006) Smoking Status as a Prognostic Factor in Patients with Stage I Pulmonary Adenocarcinoma. The Annals of Thoracic Surgery, 81, 1189-1193. https://doi.org/10.1016/j.athoracsur.2005.09.028

[12] Nancy, L.G., Kursad, T. and Kimberly, H. (2009) Impact and Interactions between Smoking and Traditional Prognostic Factors in Lung Cancer Progression. Lung Cancer, 66, 386-392. https://doi.org/10.1016/j.lungcan.2009.02.012

[13] Videtic, G.M.M., Stitt, L.W., Dar, A.R., Kocha, W.I., Tomiak, A.T., Truong, P.T., Vincent, M.D. and Yu, E.W. (2003) Continued Cigarette Smoking by Patients Receiving Concurrent Chemoradiotherapy for Limited-Stage Small-Cell Lung Cancer Is Associated with Decreased Survival. Journal of Clinical Oncology, 21, 1544-1549. https://doi.org/10.1200/JCO.2003.10.089

[14] Blanchon, F., Grivaux, M. and Collon, T. (2002) Epidemiologic of Primary Bronchial Carcinoma Management in the General French Hospital Centers. Revue des Maladies Respiratoires, 19, 727-734.

[15] Wilde, J., Haenselt, V. and Luft, D. (1990) The Relationship of Histological Type 
and Tumor Location to Prognosis in 1000 Patients with Lung Resection with Special Reference to Adenocarcinoma. Pneumologie, 44, 1287-1293.

[16] Capewell, S. and Sudlow, M.F. (1990) Performance and Prognosis in Patients with Lung Cancer. The Edinburgh Lung Cancer Group. Thorax, 45, 951-956.

[17] Wakelee, H.A., Bernardo, P., Johnson, D.H. and Schiller, J.H. (2006) Changes in the Natural History of Non Small Cell Lung Cancer (NSCLC) - Comparison of Outcomes and Characteristics in Patients with Advanced NSCLC Entered in Eastern Cooperative Oncology Group Trials before and after 1990. Cancer, 106, 2208-2217. https://doi.org/10.1002/cncr.21869

[18] Caro, J.J., Salas, M., Ward, A. and Goss, G. (2001) Anemia as an Independent Prognostic Factor for Survival in Patients with Cancer: A Systemic, Quantitative Review. Cancer, 91, 2214-2221. https://doi.org/10.1002/1097-0142(20010615)91:12<2214::AID-CNCR1251>3.0.CO; $\underline{2-\mathrm{P}}$

[19] Takigawa, N., Segawa, Y., Okahara, M., Maeda, Y., Takata, I., Kataoka, M. and Fujii, M. (1996) Prognostic Factors for Patients with Advanced Non-Small Cell Lung Cancer: Univariate and Multivariate Analyses Including Recursive Partitioning and Amalgamation. Lung Cancer, 15, 67-77.

https://doi.org/10.1016/0169-5002(96)00571-5

[20] Kasuga, I., Makino, S., Kiyokawa, H., Katoh, H., Ebihara, Y. and Ohyashiki, K. (2001) Tumor-Related Leukocytosis Is Linked with Poor Prognosis in Patients with Lung Carcinoma. Cancer, 92, 2399-2405. https://doi.org/10.1002/1097-0142(20011101)92:9<2399::AID-CNCR1588>3.0.CO;2-W

[21] Aoe, K., Hiraki, A., Ueoka, H., Kiura, K., Tabata, M., Tanaka, M. and Tanimoto, M. (2004) Thrombocytosis as a Useful Prognostic Indicator in Patients with Lung Cancer. Respiration, 71, 170-173. https://doi.org/10.1159/000076679

[22] Shafiq, M. and Venkateshiah, S. (2011) Hematologic Abnormalities Associated with Lung Carcinoma. Respiratory Care, 56, 523-526. https://doi.org/10.4187/respcare.00944

[23] Petrelli, F., Cabiddu, M., Coinu, A., Borgonovo, K., Ghilardi, M., Lonati, V. and Barni, S. (2015) Prognostic Role of Lactate Dehydrogenase in Solid Tumors: A Systematic Review and Meta-Analysis of 76 Studies. Acta Oncologica, 54, 961-970. https://doi.org/10.3109/0284186X.2015.1043026

[24] Lee, D.S., Park, K.R., Kim, S.J., Chung, M.J., Lee, Y.H., Chang, J.H., Kang, J.H., Hong, S.H., Kim, M.S. and Kim, Y.S. (2016) Serum Lactate Dehydrogenase Levels at Presentation in Stage IV Non-Small Cell Lung Cancer: Predictive Value of Metastases and Relation of Survival Outcomes. Tumor Biology, 37, 619-625. https://doi.org/10.1007/s13277-015-3776-5

[25] Espinosa, E., Feliu, J., Zamora, P., Gonzalez Baron, M., Sanchez, J.J., Ordonez, A. and Espinosa, J. (1995) Serum Albumin and Other Prognostic Factors Related to Response and Survival in Patients with Advanced Non-Small Cell Lung Cancer. Lung Cancer, 12, 67-76. https://doi.org/10.1016/0169-5002(95)00407-R

[26] Hara, M., Matsuzaki, Y., Shimuzu, T., Tomita, M., Ayabe, T., Enomoto, Y. and Onitsuka, T. (2007) Preoperative Serum C-reactive Protein Level in Non-Small Cell Lung Cancer. Anticancer Research, 27, 3001-3004.

[27] Alifano, M., Falcoz, P.E., Seegers, V., Roche, N., Schussler, O., Younes, M., Antonacci, F., Forgez, P., Dechartres, A., Massard, G., Damotte, D. and Régnard, J.F. (2011) Preresection Serum C-Reactive Protein Measurement and Survival among Patients with Resectable Non-Small Cell Lung Cancer. The Journal of Thoracic and Cardi- 
ovascular Surgery, 142, 1161-1167.

[28] Jing, X., Huang, C., Zhou, H., Li, C., Fan, L., Chen, J., Zhang, G., Liu, Y., Cui, Z., Qi, D. and Ma, J. (2015) Association between Serum C-Reactive Protein Value and Prognosis of Patients with Non-Small Cell Lung Cancer: A Meta-Analysis. International Journal of Clinical and Experimental Medicine, 8, 10633-10639.

[29] Wao, H., Mhaskar, R., Kumar, A., Miladinovic, B. and Djulbegovic, B. (2013) Survival of Patients with Non-Small Cell Lung Cancer without Treatment: A Systematic Review and Meta-Analysis. Systematic Reviews, 2, Article No. 10. https://doi.org/10.1186/2046-4053-2-10

[30] Baggstrom, M.Q., Stinchcombe, T.E. and Fried, D.B. (2007) Third-Generation Chemotherapy Agents in the Treatment of Advanced Non-Small Cell Lung Cancer: A Meta-Analysis. Journal of Thoracic Oncology, 2, 845-853.

https://doi.org/10.1097/JTO.0b013e31814617a2 